\title{
ENQUADRAMENTO SEMÂNTICO-PRAGMÁTICO DOS ITENS AINDA E AINDA SÓ: UM OLHAR PARA A VARIEDADE DO PORTUGUÊS FALADO EM ANGOLA
}

\author{
SEMANTIC-PRAGMATIC FRAMEWORK OF $A I N D A$ \\ AND AINDA SÓ: A LOOK AT THEVARIETY OF \\ PORTUGUESE SPOKEN IN ANGOLA
}

\author{
Ana Alexandra Silva \\ Universidade de Évora \\ analexandra@gmail.com \\ Luís Chimuku \\ Universidade de Évora \\ chimucoluis0@gmail.com
}

\section{RESUMO:}

No âmbito da variação linguística, procuraremos, no presente estudo, refletir em torno dos itens ainda e ainda só, no português falado em Angola. Neste país, o português apresenta marcas típicas (de natureza sintática, morfológica, fonético-fonológica e semântico-pragmática), embora ainda não possua instrumentos normalizadores, como gramáticas e dicionários específicos desta variante. O caso que agora nos ocupa pretende destacar as diferenças semântico-pragmáticas que se observam no português em Angola e identificar os desvios que neste âmbito existem em relação à norma padrão. Para a concretização dos nossos objetivos, usaremos os textos produzidos por alunos da $7^{\text {a }}$ classe do sistema de ensino angolano.

PALAVRAS-CHAVE: variação linguística; semântica e pragmática; "ainda" e "ainda só";

\begin{abstract}
In the context of linguistic variation, we will seek, in the present study, to reflect around the items "ainda" and "ainda só" in Portuguese spoken in Angola. In this country, the Portuguese has typical marks (syntactic, morphological, phonetic, phonological and semantic-pragmatic), though not yet have standard-setting instruments such as grammars and dictionaries of this specific variant. The present case is intended to highlight the semantic-pragmatic differences observed in Portuguese in Angola and to identify the
\end{abstract}


deviations that exist in this area in relation to the standard norm. To achieve our goals, we will use the texts produced by students of the 7 th grade of the Angolan education system.

KEYWORDS: linguistic variation; semantics and pragmatics: "ainda" and "ainda só"

\section{Introdução}

O contacto linguístico e os fatores extralinguísticos, nomeadamente os contextos socioculturais, históricos e geográficos, aos quais os indivíduos estão expostos contribuem para o surgimento de uma nova variedade.

Em Angola, o português apresenta marcas fonético-fonológicas, morfossintáticas, semântico-pragmáticas peculiares, motivadas, sobretudo, pelo convívio que mantém com as línguas de origem bantu, cujas estruturas em muito diferem.

Refletindo sobre o português de África, da Ásia e da Oceânia, Cunha e Cintra (1984, p.17) afirmam que o português falado nestes territórios tem como base a variedade europeia, todavia mais ou menos modificado, caracterizando-se pelo emprego de um vocabulário proveniente das línguas nativas e com aspetos fonológicos e gramaticais próprios.

Como se sabe, o português apresenta, até ao momento, apenas duas variedades estabilizadas, com normas padrão reconhecidas (caso de Portugal e do Brasil). Entretanto, não será menos verdade afirmar que nos outros pontos onde se fala essa língua se registam algumas especificidades linguísticas, apesar de não possuírem ainda instrumentos normalizadores, como gramáticas e dicionários específicos.

Apesar de oficialmente estabelecer-se a variedade do português europeu como norma padrão para Angola, as marcas da variedade angolana estão muito presentes no discurso dos falantes, mesmo em ambientes mais formais. Como bem observa Mingas (1998, p.115), "pensamos que, no nosso país, o "português de Angola" sobrepor-se-á ao "português padrão" como língua segunda dos Angolanos".

Visando aprofundar os estudos que têm sido realizados em torno da situação sociolinguística de Angola (Mingas, 2000; Barros, 2002; Fernandes \& Ntondo, 2002; Undolo, 2014 e outros) e, desta forma, contribuir para a descrição do português ali falado, propomo-nos, no âmbito da variação linguística, 
analisar alguns aspetos semânticos e pragmáticos dos itens ainda e ainda só, identificando em que contextos e com que objetivos comunicativos os falantes deste país africano os usam.

Realizámos um estudo de caso no Complexo Escolar Teresiano de Viana ${ }^{1}$ onde trabalhámos com 63 alunos da sétima classe, com idades compreendidas entre 12 e 14 anos. Orientámos estes adolescentes a redigirem uma narrativa sobre a família, sendo que ao longo do texto deveriam enquadrar os itens lexicais em estudo. Assim, seria possível apurar se os usos refletiriam os contextos previstos pela norma padrão. A totalidade dos textos serviu para a constituição do corpus.

Considerando os itens ainda e ainda só como fazendo parte da categoria adverbial, no ponto que se segue apresentaremos algumas considerações em torno desta classe; descreveremos, de acordo com a norma, os valores semânticos destes itens; na parte final, analisaremos as suas situações de uso na variedade angolana.

\section{Enquadramento teórico dos advérbios}

A teorização dos advérbios é bastante problemática na medida em que há muita divergência entre os estudiosos, nomeadamente na nomenclatura, na classificação e função, ou mesmo, na forma e no significado. Por esta razão, Cunha e Cintra (2014, p. 672) observam que "se nota entre os linguistas modernos uma tendência de reexaminar o conceito de advérbio, limitando-o seja do ponto de vista funcional, seja do ponto de vista semântico".

Esta categoria de palavra é bastante heterogénea ${ }^{2}$, tornando complexas a sua identificação e interpretação, tal como confirma Costa:

Esta heterogeneidade de comportamento dos advérbios faz com que esta categoria assuma, nalguma tradição gramatical, um caráter bastante residual, ou seja, surgem, por vezes, classificadas como advérbios todas as palavras que não satisfazem nenhum dos critérios claros para a sua inclusão numa das outras classes de palavras (COSTA, 2008, p.16)

Escola situada na Estalagem, um dos bairros periféricos da província de Luanda.

2 Sobre a heterogeneidade dos advérbios, podem ler-se Cunha e Cintra (1984); Ana e Costa (2001); Costa (2008); Silva (2009). 
Costa cita como exemplo a palavra eis que na tradição gramatical é classificada como um advérbio de designação. $\mathrm{O}$ autor considera que esta palavra possui poucas propriedades que a aproximam dos outros advérbios, como é o facto de não surgir em contextos frásicos, com exceção quando é seguido de um pronome relativo (como se exemplifica em 1a) ou quando a palavra eis é seguida de que (como em $1 b$ ).

1. a. Eis o Pedro que deu um livro à Ana.

b. Eis que o Pedro deu um livro à Ana.

Outra razão apontada pelo autor reside no facto de eis poder atribuir caso acusativo ao sintagma nominal que o segue, como abaixo se exemplifica.

2. a. Ei-lo.

b. Ei-los.

Machado (1996, p. 2), no seu estudo sobre a sintaxe dos advérbios de modo em português, considera a heterogeneidade das expressões que estão sob esta designação, o tipo de distribuição dos advérbios nas frases, bem como a ambiguidade semântica que frequentemente criam, desencadeando imprecisões nos limites desta classe.

Por esta razão, Câmara Jr. (2004, p. 77) propõe três critérios para a classificação de uma palavra: i) o critério funcional, referente a aspetos sintáticos, ou seja, ao papel da palavra na frase; ii) o critério formal, isto é, a morfologia da unidade lexical em causa; e iii) o critério semântico, que se refere ao modo como uma língua se incorpora no universo.

Sobre o critério funcional, Cunha e Cintra (1984, p. 365) afirmam que "o advérbio é, fundamentalmente, um modificador do verbo" e que "a essa função básica, geral, certos advérbios acrescentam outras que lhes são privativas." Para esses autores, a par dos advérbios terem como função principal modificar os verbos, certos advérbios, como os de intensidade e outros semanticamente correlatos, podem reforçar o sentido de um adjetivo ou do próprio advérbio. Admitem ainda que alguns advérbios podem mudar toda a oração.

Nas demais definições que se seguem, desde os primórdios dos estudos gramaticais do português aos mais recentes, os advérbios são caracterizados como simples modificadores revelando uma certa generalidade conceitual:

a. "Advérbio é uma palavra invariável que serve para modificar, ou um verbo, um adjetivo, outro advérbio, ou uma preposição". (Monteverde, 1870, p.111) 
b. "As palavras que se juntam a verbos para lhes modificar a significação e exprimir circunstâncias de uma ação, qualidade ou estado, chamamse advérbios. Podem juntar-se também a adjetivos e advérbios, exprimindo, geralmente, o grau de qualidade ou de modo." (Figueiredo e Ferreira, 1987, p. 299)

c. "Advérbio é a expressão modificadora que por si só denota uma circunstância (de lugar, de tempo, modo, intensidade, condição, etc.) e desempenha na oração a função de adjunto adverbial". (Bechara, 2009, p. 242).

Consideramos que a classificação dos advérbios, na sua totalidade, como simples modificador é muito reducionista, pois tal posicionamento coloca esta classe de palavras como um elemento acessório, facultativo, realidade que não se verifica em todas as situações.

Por exemplo, se dissermos i) "Vivo aqui desde o ano passado", a palavra destacada desempenha um papel crucial para a compreensão ou a verdade que se quer transmitir, já que ii) "Vivo desde o ano passado" não nos parece ser um enunciado muito aceitável, salvo se estiver a ser dito por uma criança de um ano de idade (muito improvável) ou em contextos de um diálogo em curso no qual se pode implicitar a verdade discursiva.

Quanto a este aspeto funcional, o Dicionário Terminológico, documento de referência para a terminologia gramatical prevista nos programas de ensino para os diferentes anos de escolaridade, parece-nos mais abrangente ao afirmar o seguinte:

Na maior parte dos casos, os advérbios desempenham a função sintática de modificadores de frase, modificadores do grupo verbal ou a função sintática de complemento oblíquo ou predicativo do sujeito. Alguns advérbios podem, ainda, modificar grupos preposicionais, grupos adjetivais ou grupos nominais.

Para além da problemática da função, outra questão que também se coloca prende-se com a sua morfologia. Há uma certa divergência entre os estudiosos se se trata de uma palavra variável ou invariável.

A título de exemplo, o Dicionário Terminológico, ao referir-se a esta matéria, considera os advérbios como "palavra invariável em género e em número". Mais adiante, admite a possibilidade de certos advérbios variarem em grau. Todavia, Koch e Silva (2003, p. 32) observam que "o grau não pode ser visto como flexão, mas como um processo de formação de palavras por derivação". 
Na abordagem que faz sobre a classe dos advérbios no Português Europeu, Costa coloca a morfologia desta categoria de palavras nos seguintes termos:

Os advérbios são palavras invariáveis, não apresentando marcas de flexão de concordância em número, género ou pessoa ou tempo, modo ou aspeto. Aproximam-se, assim, de outras classes de palavras como as preposições ou as conjunções, distinguindo-se de adjetivos, nomes ou verbos. Não obstante, na sua formação, é possível identificar alguns processos morfológicos. (COSTA, 2008, p. 27)

Mais adiante, um pouco próximo da posição de Koch e Silva, Costa desenvolve esta possibilidade de identificarmos alguns processos morfológicos nos advérbios, designadamente os advérbios que têm a mesma forma do adjetivo, os chamados advérbios adjetivais; o caso dos advérbios em -mente; e a variação em grau dos advérbios em -mente. Portanto, este autor também não encara o grau como condição para tornar o advérbio como classe de palavras variáveis, tal como atesta nas primeiras palavras da citação acima descrita.

Diferentemente desta posição, Moreira e Pimenta (2017, p.144) classificam o advérbio como "palavra que apenas admite variação em grau (em certos casos), pertencente a uma classe aberta (...)"

Barros (2015, p.103) classifica o advérbio como "pertencente a uma classe aberta de palavras, invariável, que modifica outras palavras, tal como verbos, adjetivos e outros advérbios".

Para Vilela (1999, p. 240), "os advérbios são classificados, por via de regra, como invariáveis, embora admitam graduação e mesmo mobilidade derivacional". Ora, a inclusão de "por via de regra, invariáveis", na definição dos advérbios, permite-nos interpretar que, em alguns casos, esta classe de palavras pode apresentar variação.

Não encontrámos consenso nas variadas fontes consultadas sobre se o advérbio é uma palavra variável ou invariável, confirmando-se, mais uma vez, a sua complexidade.

Depois de uma breve descrição sobre a função e morfologia dos advérbios, trataremos com mais profundidade da sua classificação semântica por ser o foco do nosso estudo. 


\section{Classificação semântica dos advérbios}

A nomenclatura dos advérbios em função da circunstância ou da ideia que expressam constitui também uma controvérsia entre os estudiosos.

Cunha e Cintra (1984, p. 366-367), na obra Nova Gramática do Português Contemporâneo, apresentam primeiramente sete subclasses de advérbios de acordo com a Nomenclatura Gramatical Brasileira, designadamente os advérbios de afirmação, dúvida, intensidade, lugar, modo, negação e de tempo. A par destas acrescentam três da Nomenclatura Gramatical Portuguesa, os advérbios de ordem, exclusão, e de designação. De forma destacada, adicionam os advérbios interrogativos e relativo.

Para além da classificação tradicional, Costa e Costa (2001, p. 21-31), na sua obra $O$ que é um advérbio? e Silva (2009, p. 261-264), na obra Estatuto sintático dos «advérbios»: função e classe, falam ainda em advérbios orientados para o agente, orientados para o falante, de foco e advérbios de realce, como abaixo se explica.

a. Advérbios Orientados para o Agente, assim designados por predicarem sobre o sujeito. Cita-se como exemplo, "O Pedro atenciosamente fez um bolo depressa" em que apenas o segundo advérbio se refere ao modo como a ação foi feita.

b. Advérbios Orientados para o Falante, que denotam uma avaliação por parte do falante, como em "Felizmente, o Pedro fechou a porta" ou em "Surpreendentemente, o Pedro entornou o café".

c. Advérbios de Foco, que impõem uma interpretação exaustiva de um determinado constituinte como em "O Pedro só entornou o café", cuja paráfrase seria "A única coisa que o Pedro fez foi entornar o café".

d. Advérbios de Realce, cuja função é a de enfatizar um determinado constituinte, como se exemplifica em "Mesmo o Pedro leu o livro" ou "Até o Pedro leu o livro".

O Dicionário Terminológico classifica os advérbios em de predicado (que engloba os de tempo, modo e lugar, na tradição gramatical), de frase, conectivo, de negação, de afirmação, de quantidade e grau (de intensidade, na tradição gramatical), de inclusão e exclusão, interrogativo e relativo. A mesma classificação encontramos em Barros (2015, p. 103-107).

Costa (2008, p. 72-75) designa advérbios de polaridade aos comummente conhecidos por advérbios de afirmação e de negação. 
Sobre a nomenclatura dos advérbios, podemos concluir que em alguns casos verifica-se a inclusão de novas subclasses e noutros a diferença reside apenas na designação.

\subsection{Valores semânticos de "ainda" $e$ "só"}

A noção de desvio passa necessariamente pelo conhecimento daquilo que a norma padrão estabelece. Nesta linha de pensamento, para facilmente detetarmos os valores semânticos que os alunos atribuíram às palavras em estudo e identificarmos quais os previstos na norma e quais estão à margem, apontando para um caso particular da variedade do português falado em Angola, pareceu-nos estratégico apresentar, primeiramente, os respetivos valores em conformidade com a norma padrão.

\subsubsection{Semântica do advérbio "ainda"}

De acordo com o Compêndio de Gramática Portuguesa (1987), o Dicionário Integral- Língua Portuguesa (2012), bem como a Gramática Moderna da Língua Portuguesa (2010), a palavra ainda é classificada como um advérbio e pode encerrar os seguintes valores temporais:

a. Até este exato momento; até agora;

3. O pai ainda não chegou de viagem.

b. naquele momento passado; até então;

4. Quando nós saímos da festa, as crianças ainda estavam lá.

c. num instante recente; agora mesmo;

5. Ainda há pouco ouvi três disparos.

d. que tende a chegar num tempo futuro; até lá;

6. Quando regressares, ainda estarei frequentando este curso.

e. num certo dia; algum dia indeterminado;

7. Um dia ainda serei famoso.

Raposo et al. (2013, p. 1653-1654) apontam três valores semântico-pragmáticos do advérbio ainda, designadamente:

a. em situações episódicas ou eventos durativos no seu decurso, assinalando que a situação descrita pela frase subsiste, introduzindo ao mesmo tempo uma pressuposição dos interlocutores de que já poderia ou deveria ter terminado, e a expetativa de que nalgum momento futuro terminará; 
8. a. Os pintores ainda estão a trabalhar.

b. A Maria ainda frequenta a universidade.

b. em situações concluídas, assinalando que a situação descrita pela frase ocorreu, mas no limite final de um determinado momento ou intervalo, por vezes contra as expetativas dos interlocutores;

9. a. O bebé ainda nasceu hoje.

b. Portugal ainda marcou um golo mesmo no fim do jogo.

c. com um tempo semântico futuro, indicando a expetativa dos interlocutores de que a situação descrita pela frase se realizará no limite final de um determinado momento ou intervalo futuro.

10. a. O bebé ainda vai nascer.

b. Portugal ainda vai marcar um golo.

\subsubsection{Semântica do advérbio "só"}

De acordo com o Dicionário Integral- Língua Portuguesa (2012), a palavra só, do latim, solu, pode ser classificada morfologicamente como um adjetivo, ou advérbio.

Como adjetivo, pode significar solitário; que está sem companhia; ermo; único; isolado; afastado da convivência social. Se funcionar como advérbio, significa apenas; somente.

O Compêndio de Gramática Portuguesa (1987) bem como a Gramática Moderna da Língua Portuguesa (2010) classificam a palavra só como um advérbio de exclusão.

Ora, depois do que foi exposto, podemos formular algumas frases com o intuito de apontar o valor semântico normativo desta unidade.

11. a. Ela, nos últimos tempos, tem-se sentido extremamente só.

b. As crianças ficaram sós, enquanto todos saíram.

Atesta-se que por se tratar da palavra só como adjetivo, a flexão torna-se evidente, concordando com o respetivo substantivo. 
Quando o sentido se referir a somente ou apenas, isto é, denotando exclusão, constatamos estar diante de um advérbio, não sendo permitida a sua flexão.

12. Os nossos vizinhos só gostam do filho mais novo.

\section{Uso dos itens ainda e ainda só no contexto angolano}

Analisar o uso de ainda e ainda só no contexto da variante do português falado em Angola leva-nos, inevitavelmente, a mergulhar no domínio da semântica e da pragmática, pois se por um lado está em causa o significado que cada unidade lexical encerra em si, bem como a relação que estabelecem entre si numa frase, do outro está o sentido que as mesmas unidades ganham em situações concretas de comunicação, envolvendo, muitas vezes, elementos extralinguísticos, como, por exemplo, a relação existente entre os interlocutores e todo o ambiente envolvente (social, cultural...).

O exercício que tem sido levado a cabo por muitos estudiosos prende-se com a delimitação entre o campo de atuação da Semântica e o da Pragmática, já que para estas duas áreas do saber o significado representa o seu objeto de estudo.

Como se sabe, estudar o significado duma palavra, frase ou de um enunciado não é tarefa fácil pois, às vezes, "é tão vago, insubstancial e inapreensível que se torna impossível chegar a uma conclusão relativamente clara ou tangível sobre as suas características" (Oliveira, 1996, p. 333).

Para esta autora, a Semântica estuda o significado expresso em palavras, sintagmas e frases, independentemente do seu uso por indivíduos específicos em situações concretas.

Na mesma linha, Lopes e Rio-Torto (2007, p.13) afirmam que a Semântica se ocupa dos significados explícitos, convencionais e invariantes das expressões linguísticas que permanecem estáveis independentemente das situações de uso. Embora muito interligadas, a Semântica distingue-se da Pragmática por esta se preocupar com o "modo como as palavras são usadas pelos utentes da língua para atingir os seus fins comunicativos" (Lima, 2006, p. 14).

Assim, "a Pragmática está além da construção da frase, estudada na Sintaxe, ou do seu significado, estudado pela Semântica. A Pragmática estuda essencialmente os objetivos da comunicação (Nascimento, 2010, p. 19).

Gouveia distingue a Pragmática de outras disciplinas nos seguintes termos: 
Enquanto a fonologia, a morfologia, a sintaxe e a semântica se centram no estudo das línguas como sistemas formais de elementos e de regras de combinação dos mesmos, a pragmática encara as línguas como instrumentos de ação e de comportamento, também eles regidos por regras, dando simultaneamente conta da relação existente entre as línguas enquanto sistemas formais e a sua atualização em sistemas de uso. (GOUVEIA, 1996, p. 383)

A Pragmática combina aspetos estruturais com os de natureza funcional da língua. Se, por exemplo, nos depararmos com um enunciado como "A porta está aberta", podemos desenhar três cenários: i) pode significar um convite para alguém entrar num dado lugar; ii) pode ser sinónimo de expulsão; iii) ou simplesmente significar que não há obstáculo, quer para sair quer para entrar. Portanto, o contexto ajudará a dissipar as eventuais dúvidas.

É precisamente nesta perspetiva de não olhar apenas a língua como sistema, mas também para a sua vertente funcional que conduziremos a nossa reflexão.

Como fizemos referência na nossa nota introdutória, para análise do enquadramento semântico e pragmático dos itens ainda e ainda só no discurso dos falantes da variedade angolana do português, contámos com alguns enunciados extraídos dos textos produzidos por 63 alunos da sétima classe. Deste total de alunos, 40 são monolingues em português, representando $63,5 \%$, e 23 têm uma língua bantu como L1 e o português como L2, tal como demonstra o gráfico abaixo.

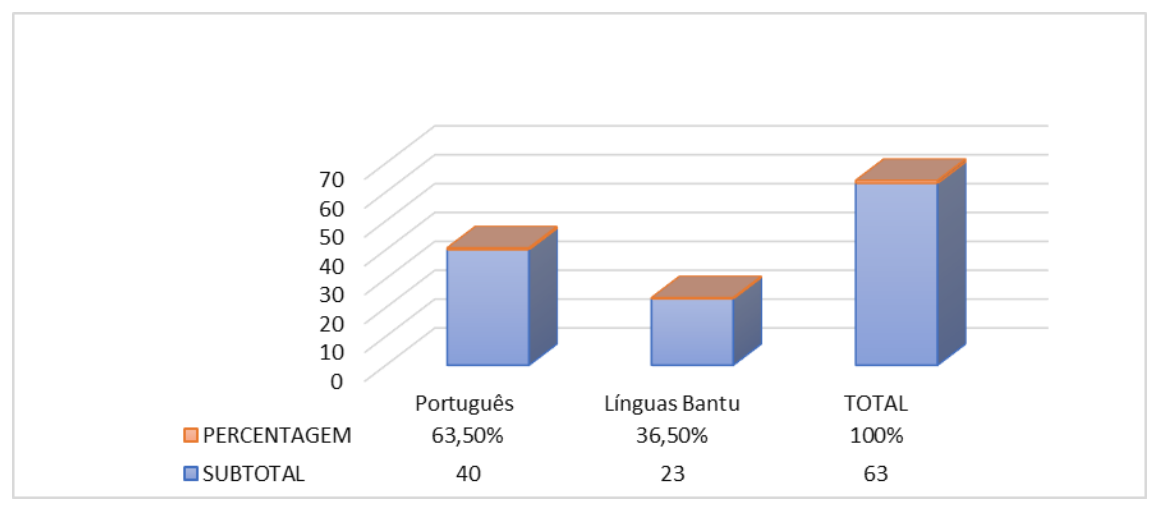

Gráfico: Língua materna dos alunos

Embora a maioria dos adolescentes com quem trabalhámos tenha o português como L1, o certo é que o input que recebe dos adultos é, geralmente, marcado por todo o tipo de interferências das línguas bantu no português, mo- 
tivando a produção de enunciados atípicos à luz do português padrão. A este processo designou-se, em Costa, por "transposição de línguas", consistindo no seguinte:

Uma criança, em idade de aquisição da linguagem, apesar de os seus pais terem a LM uma LN, aprende as primeiras palavras em português no colo da mãe, mesmo que esta não domine esta língua e que é comum vermos uma mãe a falar com a sua criança algumas palavras soltas em português, ainda que mal pronunciadas. (COSTA, 2013, p. 27)

Mais adiante, a autora avança que o facto de na época colonial o conhecimento da língua portuguesa ter sido obrigatório e condição necessária para a promoção social criou entre os angolanos um esforço em aprendê-la. Porém, o analfabetismo da população fez tender para a adaptação das estruturas das línguas bantu ao português, fenómeno que, para Teresa Costa, é prejudicial à língua portuguesa no país, até ao momento atual.

Passemos, a título ilustrativo, a apresentar alguns extratos retirados dos vários textos produzidos em sala de aulas, para posterior análise.

\subsection{Enunciados com o item ainda}

13. a.

Paulino disse:

- Espera ainda, só estou a vestir.

13. b.

- Quando estava a conversar com a minha mãe, a minha mãe disse:

- Ainda vai chamar a Leninha.

14. a.

- Ainda não foste à escola?

E ela respondeu:

-Ainda! 
14. b.

-Já lavaste as mãos?

- Ainda, mas vou já.

15. a.

Depois o meu irmão disse:

- Pedro, não vai mais no campo porque já é tarde.

- Fala ainda se não vou sair?

16. a.

- Assim a minha colega não vão lhe convidar na festa?

- Fica calma. Já vamos lhe meter na lista. Ainda como é que ela se chama?

16. b.

A minha irmã jogava andebol e naquele domingo tinha um jogo duro e já era tarde.

- O almoço vai demorar muito? Tenho de ir jogar.

- Está quase. Ainda o jogo é a que horas?

Em 13a e b, respetivamente, "Espera ainda..." e "Ainda vai chamar...", no português europeu, com a posição mais adequada do advérbio antes do verbo, a palavra em destaque significaria "por enquanto", todavia na variedade do português falado em Angola, tanto pode ter este significado, porém, mais concretamente nos enunciados em análise, revela um tratamento de cortesia.

Normalmente, a palavra "ainda" é muito usada em Angola para diluir a imperatividade do locutor diante do seu alocutário. Mais do que questões linguísticas, a relação entre os interlocutores joga um papel fundamental para o seu uso, assim como a cultura envolvente. 
Por exemplo, em umbundu, língua bantu mais falada em Angola ${ }^{3}$ e particularmente na nossa zona de investigação, dizer apenas "Kevelela" revela uma certa superioridade por parte do locutor. Para "suavizar", ou seja, ser menos formal, dir-se-ia "Handi kevelela", cuja tradução literal seria "Espera ainda". Esta transferência do umbundu para o português é muito recorrente, sobretudo na região Centro-Sul de Angola.

Uma outra particularidade que podemos registar é o uso do advérbio de tempo "ainda" como se fosse um advérbio de negação, tal como se apresenta em 14a e b. O mais comum é o segundo caso, ou seja, quando a interrogativa começa com o "já". Lembramo-nos, aqui, quando adolescentes, de brincar às escondidas em que a pessoa a quem competia procurar pelos outros gritava "já?" e os demais respondiam "ainda!" Portanto, é muito recorrente dizermos "ainda" em vez de "ainda não".

A este propósito, Costa (2006, p. 223), na análise que faz sobre a variante sociolinguística da língua portuguesa determinada pela interferência das línguas bantu, afirma que "se assiste, muitas vezes, à reconversão de ainda não e ainda, passando este operador a desempenhar uma função cumulativa".

Usa-se a palavra "ainda", como no contexto de 15 , quando se tenciona lançar um desafio ou quando alguém nos põe à prova se somos ou não capazes de tomar determinada decisão, postura ou atitude. Assim, em vez de "Tens dúvidas de que sou capaz de sair?", diz-se "Fala ainda se não vou sair?"

Quando pretendemos que alguém nos faça lembrar de alguma coisa, podendo ser uma data, um evento ou um conceito, é comum a inclusão de "ainda". Em 16a, se retirarmos a palavra destacada fica "Como é que ela se chama?", implicando que o emissor nunca soube o nome da pessoa em questão. Entretanto, ao perguntar “Ainda como é que ela se chama?" pressupõe-se que sabia o nome, mas, naquele momento, não se lembrava. O mesmo pode dizer-se do enunciado em 16b. Ao perguntar "Ainda o jogo é a que horas?" implica que num dado momento já se lhe tinha dito a hora e que se tinha esquecido.

\footnotetext{
De acordo com os dados avançados pelo INE, fruto do Recenseamento Geral da População e Habitação realizado em 2014, mais de metade da população (71\%) fala português, com maior predominância nas áreas urbanas ( $85 \%$ da população) ao passo que na área rural somente $49 \%$ da população fala essa língua. O umbundu é a segunda língua mais falada, 23\%, seguindo-se o kikongo e o kimbundu com cerca de 8\% cada. (cf. INE. Luanda, Angola - 2016 em https:// www.ine.gov.ao/)
} 


\subsection{Enunciados com a expressão "ainda só"}

17. a.

- Mãe, ainda deixa-me só ajudá-la a levar a mala.

17. b.

- Vamos falar a Mãe para ir já ao mercado para comprar as coisas necessárias para a festa.

A mãe respondeu:

- Vou só ainda tomar um banho e vou já.

17. c.

Respondi ao meu pai:

- Está bem, pai. Ainda só vou me despedir dos amigos.

17. d.

- Mas ainda só vou chamar o meu amigo Vado.

Disse-me:

- Vai, mas não demores!

A combinação entre os advérbios ainda e só também é muito recorrente no português falado em Angola, embora em muitos contextos percam este valor adverbial, de tempo e de exclusão, respetivamente.

A posição destas duas unidades lexicais não é uniforme, ou seja, podem aparecer de forma intercalada, como em 17a; com a anteposição de só, como em 17b; ou ainda com a anteposição de ainda, como em 17c e d.

Embora a coexistência de ainda e só seja possível num enunciado da variante padrão, entenda-se do $\mathrm{PE}$, como em "Ainda só consegui uma bola para o jogo de amanhã", equivalendo a "Até ao momento apenas consegui uma bola...", o certo é que estes itens não funcionam de forma combinatória, pois cada unidade lexical conserva o seu valor semântico dentro do enunciado. 
Contrariamente, na variante do português falado em Angola, os dois itens funcionam como uma locução ${ }^{4}$ gramatical, todavia com um pendor mais pragmático que semântico.

De qualquer forma, o valor semântico-pragmático mais usual para esta combinação é o de pedido de autorização, permissão ou licença para fazer alguma coisa, como se disséssemos, por exemplo, "Importa-se que eu vá despedir-me dos amigos?".

Esta combinação também é muito usual em umbundu, todavia a mobilidade dos dois constituintes é muito limitada, tal como podemos exemplificar.

17. e. Handi ndenda ñgo kondjo.

17. f. * Ñgo ndenda handi kondjo.

Portanto, em 17e, encontra-se a "fórmula" mais comum para um pedido de licença nesta língua bantu mais falada em Angola, cuja tradução literal seria "Ainda vou só a casa" e, de acordo com a norma padrão, teríamos "Permita-me que vá a casa".

O enunciado em 17f é agramatical, pois a posição regular de "ñgo" [só] é pós-verbal, diferentemente do que acontece em português, cuja mobilidade é possível, tal como já o demonstrámos.

\section{Conclusão}

Visando estudar alguns aspetos da variedade do português falado em Angola, levámos a cabo um estudo de caso, numa escola, com os alunos do I ciclo do ensino secundário (da $7^{\mathrm{a}}$ classe). Com esta pesquisa, pretendíamos identificar alguns valores semântico-pragmáticos de certos advérbios, contrastando aquela variante africana com a norma padrão europeia.

Importa referir que os valores normativos dos advérbios em análise também estão presentes na realidade linguística angolana. Todavia, a par destes, surgiram outros, tal como demonstrámos. Em certos casos, algumas unidades lexicais perderam o valor adverbial, imprimindo um valor de cortesia, de formalidade, portanto puramente pragmático, resultante da tradução literal da estrutura das línguas bantu.

Embora se procure a todo o custo forjar a variedade padrão do português,

4 Sobre os critérios para a construção de locuções adverbiais, conferir Costa (2008: 22), na obra O Advérbio em Português Europeu. 
nas escolas, na imprensa e na administração pública em geral, o certo é que devido a fatores linguísticos e extralinguísticos as marcas que caracterizam o português falado em Angola acabam sempre se evidenciando, tanto se trate de contextos informais como formais, razão pela qual muitos estudos têm vindo a advogar, no âmbito da política linguística, a normatização da variedade angolana do português, aproximando-se, assim, às particularidades sociolinguísticas do país.

\section{Referências}

BARROS, Agnela. A situação do português em Angola. In: MATEUS, Maria Helena Mira (ed.). Uma Política de Língua para o Português. Lisboa: Colibri, 2002, p. 35-44.

BARROS, Vítor. Nova gramática de português: língua estrangeira e língua segunda. Lisboa: Edições Colibri, 2015.

BECHARA, Evanildo. Moderna gramática portuguesa. 37. Ed. Rio de Janeiro: Editora Nova Fronteira, 2009.

CÂMARA JR., Joaquim Mattoso. Estrutura da língua portuguesa. 36. ed. Petrópolis: Vozes, 2004.

COSTA, António. Ruturas estruturais do português e línguas bantu em Angola: para uma análise diferencial. Luanda: Universidade Católica de Angola, 2006.

COSTA, Ana; COSTA, João. O que é um advérbio? Lisboa: Edições Colibri, 2001.

COSTA, João. O advérbio em português europeu. Lisboa. Edições Colibri, 2008.

COSTA, Teresa. Os empréstimos das línguas bantu no português falado em Angola. Luanda: Edição de Autor, 2013.

CUNHA, Celso; CINTRA, Luís Lindley. Nova gramática do português contemporâneo. Lisboa: Edições JSC, 1984.

. Nova gramática do português contemporâneo. Lisboa: Edições JSC, 2014.

.Dicionário integral - língua portuguesa. Luanda: Texto Editores, 2012.

FERNANDES, João; NTONDO, Zavoni. Angola: povos e línguas. Luanda: Nzila, 2002. 
FIGUEIREDO, José Nunes de; FERREIRA, António Gomes. Compêndio de gramática portuguesa. Porto: Porto Editora, 1987.

GOUVEIA, Carlos. Pragmática. In: FARIA, Isabel; PEDRO, Emília Ribeiro; DUARTE, Inês, GOUVEIA, Carlos A. M. Introdução à Linguística Geral e Portuguesa. Lisboa: Caminho, 1996, p. 383- 419.

KOCH, Ingedore; SOUSA E SILVA, Maria Cecília Pérez de. Linguística aplicada ao português: morfologia. São Paulo: Cortez, 2003.

LIMA, José Pinto de. Pragmática linguística. Lisboa: Editorial Caminho, 2006. LOPES, Ana; RIO-TORTO, Graça. Semântica. Lisboa: Editorial Caminho, 2007.

MACHADO, Maria. Sintaxe dos advérbios de modo em Português. Dissertação (Mestrado em Linguística). Porto: Faculdade de Letras da Universidade do Porto, 1996.

MATOS, João Carlos. Gramática moderna da língua portuguesa. Lisboa: Escolar Editora, 2010.

MINGAS, Amélia. Português de Angola: uma realidade? In: VIII Encontro da Associação das Universidades de Língua Portuguesa. Macau: Centro Cultural da Universidade de Macau, v.1, 1998, p.109-126.

MINGAS, Amélia. Interferência do kimbundu no português falado em Lwanda. Porto: Campo das Letras, 2000.

MONTEVERDE, Emilio. Manual encyclopedico para uso das escolas de instrução primária. Lisboa: Imprensa Nacional, 1870.

MOREIRA, Vasco; PIMENTA, Hilário. Gramática de português - $3 .^{\circ}$ ciclo do ensino básico e ensino secundário. Porto: Porto Editora, 2017.

NASCIMENTO, Marcos Soares do; SANTOS, Gilberlande Pereira dos (Orgs.). Pragmática: compreensão e violação das máximas conversacionais em gêneros textuais diversificados. Recife: Libertas, 2010.

OLIVEIRA, Fátima. Semântica. In: FARIA, Isabel; PEDRO, Emília Ribeiro; DUARTE, Inês, GOUVEIA, Carlos A. M. Introdução à Linguística Geral e Portuguesa. Lisboa: Caminho, 1996, p. 333- 379.

RAPOSO, Eduardo et al. Gramática do português. Lisboa: Fundação Calouste Gulbenkian, 2013.

SILVA, Ana Alexandra. Estatuto sintático dos «advérbios»: função e classe. Évora: CEL, 2009. 
UNDOLO, Márcio. Caracterização da norma do português em Angola. Tese (Doutoramento em Linguística). Évora: Universidade de Évora, 2014. VILELA, Mário. Gramática da língua portuguesa. Coimbra: Edições Almedina, 1999.

Recebido em 18 de outubro de 2019.

Aceito em 23 de janeiro de 2020. 